$17^{\text {th }}$ European Symposium on Computer Aided Process Engineering - ESCAPE17

V. Plesu and P.S. Agachi (Editors)

(C) 2007 Elsevier B.V. All rights reserved.

\title{
Design and Control of Thermally Coupled and Heat Integrated Distillation Sequences for Quaternary Separations
}

\author{
Jorge Alberto Porras-Rodríguez, Héctor Hernández-Escoto, Juan Gabriel \\ Segovia-Hernández, Salvador Hernández \\ Universidad de Guanajuato, Facultad de Química, Noria Alta s/n, Guanajuato, Gto., \\ 36050, México, E-mail: hernasa@quijote.ugto.mx
}

\begin{abstract}
In this work we have extended the design and optimization methods for the separation of quaternary mixtures of hydrocarbons. Also, a controllability analysis using the singular value decomposition technique was performed in order to obtain the control properties of the distillation schemes. One conventional distillation sequence and three thermally coupled distillation sequences have been studied: one considering a side stripper and a side rectifier, one considering a side stripper and a side rectifier and heat integration between the side columns and a Petlyuk-type column. The design of a thermally coupled system starts from a conventional distillation sequence and then the recycle streams are varied until the minimum energy consumption is detected. The results show energy savings of around $30 \%$ of the thermally coupled distillation sequences in comparison to the conventional distillation sequence. Also, the system including both thermal and heat integration presented the lowest energy demand and the highest second law efficiency. When the integrated distillation sequences were subjected to a controllability analysis, the complex distillation sequence considering both thermal and heat integration presented the worst control properties in contrast to those of the complex schemes considering only thermal couplings.
\end{abstract}

Keywords: Thermally coupled distillation, heat integration, control properties 


\section{Introduction}

Conventional distillation trains are widely used in the chemical industry, but these distillation sequences are characterized for their large demands of energy in the reboilers. As a result, researchers and engineers in process systems engineering are developing new alternatives to classical distillation sequences than can lower the demands of energy. One form of reducing the energy consumption is the use of thermally coupled distillation sequences that can achieve energy savings of up to $50 \%$ for the separation of some ternary mixtures $[1,2,3,4,5]$. Thermally coupled distillation sequences have been implemented in industrial practice and there have been reported significant savings in both energy and capital costs (BASF). Such practical implementation has been due to advances in design and optimization methods and the proper understanding of their control properties. The theoretical control properties and dynamic simulations under the action of PI controller have demonstrated that thermally coupled distillation sequences, in some cases, can outperform the dynamic behavior of the classical distillation sequences based on conventional columns. Important contributions have been made in order to implement the thermally coupled distillation sequences by using dividing-wall distillation columns. For instance, some industrial practitioners have reported important savings in the total annual cost by using thermally coupled distillation columns [6,7]. In the academia, Strandberg and Skogestad [8] have reported a preliminary study of the operation and control of an experimental Petlyuk type column used for the separation of a quaternary mixture.

Blancarte-Palacios et al. [9] and Christiansen et al. [10] have extended the ideas of thermally coupled separation to systems of quaternary mixtures. Those authors studied the conventional distillation sequence (CDS), the thermally coupled distillation sequence with a side stripper and a side rectifier (TCDSSS/SR) and a Petlyuk-type column (TCDS-PR) shown in Figures 1a-1c. Their results indicate that similar energy savings can be obtained when compared to the separation of ternary mixtures. Recently, Rong et al. [11] have reported additional energy savings including both thermal couplings and heat integration (TCDS-IN) as indicated in Figure 1c.

In this work, we calculated and compared second law efficiencies and energy consumptions required separating quaternary mixtures of hydrocarbons using the distillation sequences indicated in Figures 1. Finally, a controllabity analysis was carried out, using the singular value decomposition technique, in order to understand the effect of the thermal links and heat integration on the theoretical control properties of the conventional and complex distillation sequences. 
Design and Control of Thermally Coupled and Heat Integrated Distillation Sequences for Quaternary Separations

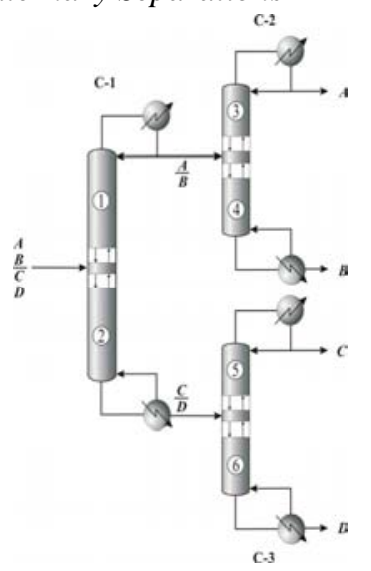

(a) CDS

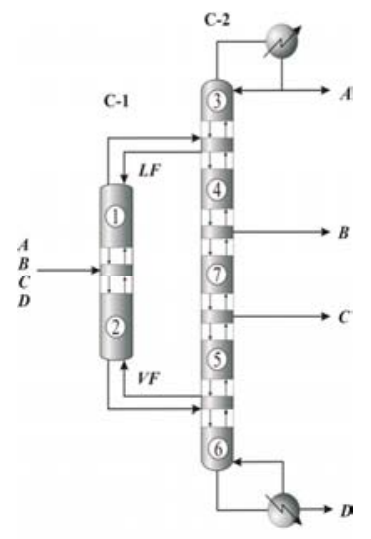

(c) TCDS-PR

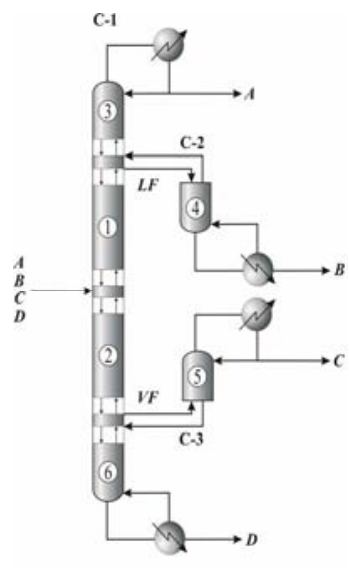

(b) TCDS-SS/SR

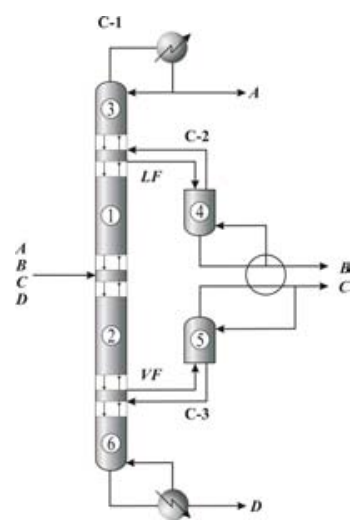

(d) TCDS-IN

Figure 1 Conventional and complex distillation schemes.

\section{Design strategy}

The design and optimization of the complex distillation schemes of Figures 1b$1 \mathrm{~d}$ are not trivial because of the recycles stream between the columns. The optimized designs were obtained in two stages: i) the conventional distillation sequence of Figure 1a was used as initialization for the optimization, and ii) the tray structures of the complex distillation sequences are obtained from the conventional distillation sequence and the recycle streams are introduced and 
varied until the minimum energy consumptions are detected. This was carried out in Aspen Plus.

For example, the design of the TCDS-IN of Figure 1d is obtained from the TCDS-SS/SR of Figure 1b using the same number of tray sections. It is important to consider that the heat duty from the condenser in column C-3 is used in the reboiler of column C-2 (Figure 1d) and pressures are set to obtain at least a difference of $10{ }^{\circ} \mathrm{C}$ between the top of column $\mathrm{C}-3$ and the bottoms of column C-2.

\section{Controllability analysis}

The controllability analysis was carried out through the use of the singular value decomposition (SVD) technique. The SVD technique requires linear models which in the frequency domain are decomposed into singular values. A complex matrix can be decomposed into three matrices according to Equation 1.

$G(j \omega)=V(j \omega) \Sigma(j \omega) W^{H}(j \omega)$

where $\Sigma(j \omega)$ is a diagonal matrix whose entries are the singular values of $G(j \omega)$. From these singular values, two of them can be used in order to obtain information about the control properties of the system: the minimum singular value $\left(\sigma_{*}\right)$, and the condition number $\left(\gamma^{*}=\sigma_{*} / \sigma^{*}\right)$; where $\sigma^{*}$ is the maximum singular value. The systems with higher minimum singular values and lower condition numbers are expected to show the best dynamic performance under feedback control. From a physical point of view, low values of the minimum singular value and high values of the condition number imply large deviations in the control valves for changes in the set points and load rejection.

\subsection{Case study}

We have considered the case of study of the separation of an equimolar fourcomponent mixture of n-pentane, n-hexane, n-heptane and n-octane, with a feed flowrate of $45.5 \mathrm{kmol} / \mathrm{h}$ as saturated liquid at $23.6 \mathrm{psia}$.

\subsection{Results \& discussions}

For the separation of the quaternary mixture of hydrocarbons, the thermally coupled distillation sequences present energy savings between 12 and 20\% (TCDS-SS/SR and TCDS-PR). According to Table 1, we can see that the introduction of heat integration in the TCDS-IN increased the energy saving up to $39 \%$. Hence, the energy savings in distillation trains can be increased through the use of both thermal links and heat integration between condensers and reboilers. 
Design and Control of Thermally Coupled and Heat Integrated Distillation Sequences for Quaternary Separations

When second law efficiencies were obtained for the conventional and complex distillation systems, the TCDS-IN presented both highest energy savings and second law efficiencies due to two thermal links and heat integration (Table 1). The thermally coupled distillation sequence with a prefractionator (TCDS-PR) presented the lowest second law efficiency because all the energy required to distill the quaternary mixture is introduced at the highest temperature in the distillation sequence.

Table 1 Energy consumptions and second law efficiencies for the distillation sequences.

\begin{tabular}{|c|c|c|c|}
\hline $\begin{array}{c}\text { Distillation } \\
\text { Sequence }\end{array}$ & $\begin{array}{c}\text { Energy } \\
\text { Consumption }(\mathrm{kW})\end{array}$ & $\begin{array}{c}\text { Energy Saving } \\
(\%)\end{array}$ & $\begin{array}{c}\text { Second Law } \\
\text { Efficiency (\%) }\end{array}$ \\
\hline CDS & 966.0 & 0.0 & 20 \\
\hline TCDS-SS/SR & 773.0 & 20.0 & 22.5 \\
\hline TCDS-PR & 851.0 & 12.0 & 10.5 \\
\hline TCDS-IN & 586.1 & 39.0 & 24.2 \\
\hline
\end{tabular}

To complete the study, the theoretical control properties were obtained for the distillation sequences. Figure 2a shows the minimum singular values, in the frequency domain, for the conventional and complex distillation sequences.

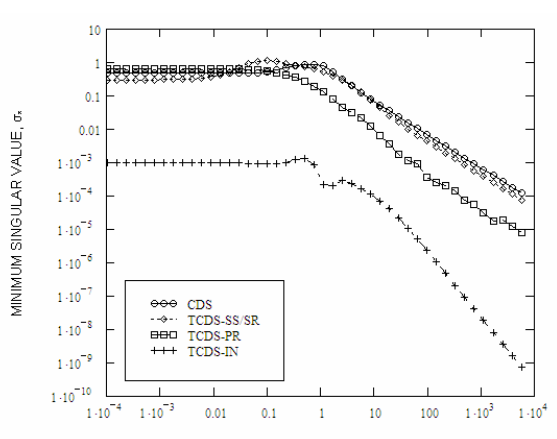

(a)

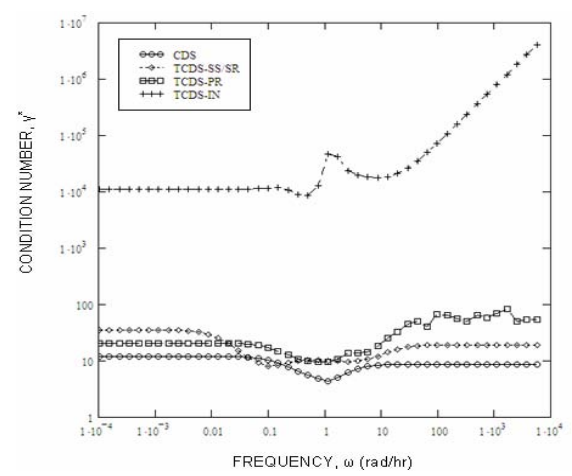

(b)

Figure 2 (a) Minimum singular values, (b) Conditions numbers for the distillation sequences.

Figure 2a shows that the TCDS-IN presents lower minimum singular values than those of the other distillation sequences. In the case of the condition number (Figure 2b) a clear tendency was obtained, i. e., the TCDS-IN presented higher values of the condition number over the whole frequency range. As a result, it should be expected that the TCDS-IN presents the worst dynamic responses under feedback control for set point tracking and load rejection in contrast to the conventional and thermally coupled distillation sequences. 


\section{Conclusions}

Energy consumptions, second law efficiencies and theoretical control properties were obtained and compared for the separation of a quaternary mixture of hydrocarbons using conventional and complex distillation sequences. When a complex distillation system with thermal and heat integration was studied, the highest values of energy savings and second law efficiencies were obtained, but this system presented the worst theoretical control properties. As a result, it can be concluded that when both thermal and heat integration are presented, higher energy savings are obtained at expense of difficulties in control and operation because of a reduction in the control variables. These results promote the use of thermally coupled distillation sequences in the chemical industry in order to save energy and capital costs.

\section{Acknowledgements}

This research project was supported by PROMEP and Universidad de Guanajuato, México.

\section{References}

1. D.W. Tedder and D.F. Rudd, AIChE J. 24 (1978) 303

2. C. Triantafyllou and R. Smith, Trans Inst. Chem. Eng. 70 (1992) 118

3. O. Annakou and P. Mizsey, Ind. Eng. Chem. Res. 35 (1996) 1877

4. S. Hernández and A. Jiménez, Comput. Chem. Eng. 23 (1999) 1005

5. A. Jiménez, S. Hernández, F.A. Montoy and M. Zavala-García, Ind. Eng. Chem. Res. 40 (2001) 3757

6. G. Kaibel and H. Schoenmarkers, Proc. ESCAPE-12 Eds. J. Grievink and J.V. Schijndel, Elsevier, Amsterdam (2002) 9

7. M.A. Schultz, D.E. O’Brien, R. K. Hoehn, C.P. Luebke and D. G. Stewart, Proc. ESCAPE-16 and PSE 2006, Eds. W. Marquardt and C. Pantelides, Elsevier, Frankfurt (2006) 695

8. J. Strandberg and S. Skogestad, Proc. Distillation and Absorption 2006, Ed. E. Sorensen, IChemE Symposium Series No. 152, London (2006) 638

9. J.L. Blancarte-Palacios, M.N. Bautista-Valdés, S. Hernández, V. Rico-Ramírez and A. Jiménez, Ind. Eng. Chem. Res. 42 (2003) 5157

10. A.C. Christiansen, S. Skogestad and K. Lien, Comput. Chem. Eng. 21 (1997) S237

11. B.G. Rong, A. Kraslawski and I. Turunen, Ind. Eng. Chem. Res. 42 (2003) 4329 